\title{
Simple and Selective Spectrophotometric Determination of Ofloxacin in Pharmaceutical Formulations Using Two Sulphonphthalein Acid Dyes
}

\author{
Kudige N. Prashanth, Kanakapura Basavaiah, and Madihalli S. Raghu \\ Department of Chemistry, University of Mysore, Karnataka, Manasagangotri, Mysore 570006, India \\ Correspondence should be addressed to Kanakapura Basavaiah; basavaiahk@yahoo.co.in
}

Received 27 February 2013; Accepted 4 April 2013

Academic Editors: A. A. Ensafi, M. Mączka, and U. Pal

Copyright (C) 2013 Kudige N. Prashanth et al. This is an open access article distributed under the Creative Commons Attribution License, which permits unrestricted use, distribution, and reproduction in any medium, provided the original work is properly cited.

\begin{abstract}
Two new simple and sensitive extraction-free spectrophotometric methods have been established for the determination of ofloxacin (OFX). The methods are based on ion-pair complex formation reaction between OFX and acidic sulphonphthalein dyes, bromocresol purple (method A), and bromocresol green (method B) in dichloromethane. The experimental variables such as reaction medium, reaction time, and reagent concentration have been carefully optimized to achieve the highest sensitivity. Both dyes react spontaneously with OFX to give yellow-colored complexes. Beer's law is obeyed over the concentration ranges of $1.0-$ $16 \mu \mathrm{g} \mathrm{ml}^{-1}$ OFX with correlation coefficient of 0.999 in both methods. The molar absorptivity values are calculated to be $2.40 \times 10^{4}$ and $1.97 \times 10^{4} 1 \mathrm{~mol}^{-1} \mathrm{~cm}^{-1}$, for method A and method B, respectively, with corresponding Sandell's sensitivity values of 0.015 and $0.019 \mu \mathrm{g} \mathrm{cm}^{-2}$. The limits of detection (LOD) and quantification (LOQ) are also reported. A Job's plot of the absorbance versus the molar ratio of OFX to each of dyes under consideration indicated (1:1) ratio and the conditional stability constant $\left(K_{F}\right)$ of the complexes have been calculated. The proposed methods were applied successfully to the determination of OFX in tablets with good accuracy and precision and without interference from common additives. The results obtained by the proposed methods were compared favorably with those of the reference method.
\end{abstract}

\section{Introduction}

Ofloxacin (OFX), (RS)-7-fluoro-2-methyl-6-(4-methylpiperazine-1-yl)-10-oxo-4-oxa-1-azatricyclo[7.3.1.05,13] trideca-5(13), 6,8,11-tetraene-11-carboxylic acid (Figure 1), is a synthetic fluorinated quinolone derivative having activity against both gram negative and gram positive bacteria through inhibition of their DNA gyrase [1]. It is widely used in the treatment of respiratory tract and urinary tract infections [2]. OFX possesses two relevant ionizable functional groups: a basic piperazinyl group and a carboxylic group. The carboxylic group and the carbonyl groups are required for antimicrobial activity. OFX is official in the United States Pharmacopoeia [3] and the British Pharmacopoeia [4], which recommend nonaqueous titrimetry [3,4] and HPLC [3] techniques for its assay in bulk and dosage forms.

A review of the literature revealed that several methods have been reported for the analysis of OFX in pharmaceutical preparations. HPLC has been used for the assay of OFX in pharmaceuticals when present either alone [5-7] or in combination with nitazoxanide [8]. Various other techniques including HPTLC [9], capillary electrophoresis [10, 11], atomic absorption spectrometry [12], spectrofluorometry [12], chemiluminescence spectrometry [13-15], UV-spectrophotometry [16-18], stripping voltammetry [19], potentiometry and conductometry [20], polarography [21], and microbiological method [22] have been reported for the assay of OFX in pharmaceuticals. Many of the above techniques are deficient on simplicity, cost-effectiveness, and easy accessibility.

The most widely used technique for the assay of OFX has been visible spectrophotometry and methods based on diverse reaction chemistries such as oxidative coupling reaction using $\mathrm{Ce}(\mathrm{IV})-\mathrm{MBTH}$ [23], condensation reaction with citric acid-acetic anhydride [24], complex formation reaction with $\mathrm{Fe}$ (III) nitrate nonahydrate [25], iron(III) chloride in $\mathrm{HCl}$ medium [26], ion pair complex with tropaeolin 000 and 
TABLE 1: Comparison of the performance characteristics of the present methods with the published methods.

\begin{tabular}{|c|c|c|c|c|c|c|}
\hline $\begin{array}{l}\text { Sl. } \\
\text { no. }\end{array}$ & Reagent(s) used & Methodology & $\begin{array}{l}\lambda_{\max } \\
(\mathrm{nm})\end{array}$ & $\begin{array}{c}\text { Linear range } \\
(\mu \mathrm{g} / \mathrm{mL}) \\
(\varepsilon=\mathrm{L} / \mathrm{mol} / \mathrm{cm})\end{array}$ & Remarks & Reference \\
\hline 1 & $\mathrm{Ce}(\mathrm{IV})-\mathrm{MBTH}$ & $\begin{array}{l}\text { Oxidative coupling reaction } \\
\text { product measured }\end{array}$ & 640 & $1-10$ & $\begin{array}{l}\text { Uses expensive reagent; less stable species } \\
\text { measured }\end{array}$ & {$[23]$} \\
\hline 2 & $\begin{array}{l}\text { Citric acid-acetic } \\
\text { anhydride }\end{array}$ & $\begin{array}{l}\text { Pink-colored chromogen } \\
\text { measured }\end{array}$ & 552 & $\begin{array}{c}5-55 \\
\left(\varepsilon=6.04 \times 10^{3}\right)\end{array}$ & Boiling for $20 \mathrm{~min}$ required & {$[24]$} \\
\hline 3 & Iron(III) nitrate & $\begin{array}{l}\text { Amber-coloured complex } \\
\text { measured }\end{array}$ & 370 & $\begin{array}{c}0-62.5 \\
\text { NA }\end{array}$ & Buffers used & {$[25]$} \\
\hline 4 & Iron(III) chloride/HCl & Yellow complex measured & 410 & $20-160$ & Less sensitive & {$[26]$} \\
\hline \multirow{2}{*}{5} & $\begin{array}{l}\text { (a) Tropaeolin } 000 \\
\text { (TP 000) }\end{array}$ & $\begin{array}{l}\text { Red chloroform extractable } \\
\text { ion-pair complex measured }\end{array}$ & 485 & $\begin{array}{c}2.5-30 \\
\left(\varepsilon=8.24 \times 10^{3}\right)\end{array}$ & \multirow{2}{*}{$\begin{array}{l}\text { Required close } \mathrm{pH} \text { control and involved } \\
\text { extraction steps }\end{array}$} & \multirow{2}{*}[27]{} \\
\hline & $\begin{array}{l}\text { (b) Supracene Violet 3B } \\
\text { (SV 3B) }\end{array}$ & $\begin{array}{l}\text { Chloroform extractable } \\
\text { ion-pair complex measured }\end{array}$ & 575 & $\begin{aligned} & 2.5-25 \\
&(\varepsilon=\left.1.09 \times 10^{4}\right) \\
&\end{aligned}$ & & \\
\hline \multirow{3}{*}{6} & (a) Bromophenol blue & & 410 & $\begin{array}{c}5-25 \\
\left(\varepsilon=1.04 \times 10^{4}\right)\end{array}$ & \multirow{3}{*}{$\begin{array}{l}\text { Required close } \mathrm{pH} \text { control and involved } \\
\text { extraction steps }\end{array}$} & \multirow{3}{*}[28]{} \\
\hline & (b) Bromothymol blue & $\begin{array}{l}\text { Yellow chloroform } \\
\text { extractable } 1: 1 \text { ion-pair } \\
\text { complex measured }\end{array}$ & 415 & $\left(\varepsilon=2.01 \times 10^{4}\right)$ & & \\
\hline & (c) Bromocresol purple & & 410 & $\begin{array}{c}2-20 \\
\left(\varepsilon=1.04 \times 10^{4}\right)\end{array}$ & & \\
\hline \multirow[t]{2}{*}{7} & & $\begin{array}{l}\text { In both methods, resulting } \\
\text { yellow-colored ion-pair }\end{array}$ & 400 & $\begin{array}{c}1.0-16.0 \\
\left(\varepsilon=2.4 \times 10^{4}\right)\end{array}$ & $\begin{array}{l}\text { Highly sensitive with wide linear dynamic } \\
\text { ranges, no heating or extraction step, no }\end{array}$ & \multirow{2}{*}{$\begin{array}{l}\text { Present } \\
\text { methods }\end{array}$} \\
\hline & (b) Bromocresol green & complexes measured & 410 & $\left(\varepsilon=1.96 \times 10^{4}\right)$ & $\begin{array}{l}\mathrm{pH} \text {-adjustment, single step reaction, and } \\
\text { inexpensive instrumental setup }\end{array}$ & \\
\hline
\end{tabular}<smiles>CC1COc2c(N3CCN(C)CC3)c(F)cc3c(=O)c(C(=O)O)cn1c23</smiles>

FIGURE 1: Chemical structure of OFX.

supracene violet $3 \mathrm{~B}[27]$ or with bromophenol blue (BPB), bromothymol blue (BTB), and bromocresol purple (BCP) [28] have been reported for the determination of OFX. Most of the above visible spectrophotometric methods suffer from one or disadvantages such as use of expensive reagents, use of heating step, poor sensitivity, liquid-liquid extraction step, and close $\mathrm{pH}$ control as indicated in Table 1.

Liquid-liquid extraction followed by absorbance measurement has many disadvantages as it is tedious, timeconsuming, labour-intensive, and very prone to loss of analyte. In response to the problem resulting from extraction of the ion pair, few articles were published for the analysis of pharmaceutical compounds through ion pair formation without extraction [29-32].

In this piece of work, two simple, ion-pair extractionfree spectrophotometric methods are proposed for the determination of OFX based on the interaction of OFX with sulphonphthalien dyes, bromocresol purple $(\operatorname{method} \mathrm{A})$, and bromocresol green (method B) in dichloromethane medium. The ion pairs formed require no extraction step and are measured directly in dichloromethane.

\section{Materials and Methods}

2.1. Apparatus. All absorbance measurements were made using a Systronics model 106 digital spectrophotometer (Ahmedabad, India) equipped with $1 \mathrm{~cm}$ matched quartz cells.

2.2. Materials and Reagents. All chemicals and reagents used were of analytical reagent grade. The solvents used were of HPLC grade; bromocresol purple BCP, (Loba Chemie, Mumbai, India) and bromocresol green BCG, (Loba Chemie, Mumbai, India); each $0.1 \%$ were prepared in dichloromethane (Merck, Mumbai, India).

Pure OFX (pharmaceutical grade) sample was kindly provided by Cipla India Ltd., Mumbai, India, and was used as received. Standard OFX solutions were prepared in dichloromethane (Merck, Mumbai, India).

Two brands of tablets, containing OFX, Zenflox-400 (Mankind Pharma Pvt. Ltd., New Delhi, India), and Ofloxin400 (J. B. Chemicals and Pharmaceuticals Ltd, Mumbai, India) used in the investigation, were purchased from local commercial sources.

\subsection{Construction of Calibration Curves}

2.3.1. General Procedure. In both methods, aliquots of 0.25 , $0.5, \ldots, 4.0 \mathrm{~mL}$ OFX standard solution in dichloromethane $(20 \mu \mathrm{g} / \mathrm{mL})$ were measured accurately and transferred into a series of $5 \mathrm{~mL}$ volumetric flask. To each flask, $1 \mathrm{~mL}$ of $0.1 \%$ each of BCP in method A and BCG in method B were added, diluted to the mark with dichloromethane, and mixed well. The absorbance of the resulting yellow color chromogen was 
measured at $400 \mathrm{~nm}$ in method $\mathrm{A}$ and at $410 \mathrm{~nm}$ in method $\mathrm{B}$ against respective reagent blank.

In both methods, a standard graph was prepared by plotting the increasing absorbance values versusconcentration of OFX. The concentration of the unknown was read from the standard graph or computed from the respective regression equation derived using the Beer law data.

2.3.2. Procedure for the Assay of OFX in Tablets. Ten tablets were accurately weighed and powdered. A portion equivalent to $25 \mathrm{mg}$ OFX was accurately weighed and transferred into a $50 \mathrm{~mL}$ volumetric flasks, $30 \mathrm{~mL}$ of dichloromethane was added to the flask and the content was shaken thoroughly for 15-20 min to extract the drug into the liquid phase; the volume was finally diluted to the mark with dichloromethane (50 mL flask), mixed well, and filtered using a Whatman no. 42 filter paper. An aliquot of the filtrate $(500 \mu \mathrm{g} / \mathrm{mL}$ in OFX) was further diluted to get the required concentrations and analyzed for OFX following the procedures described for the calibration curve.

2.3.3. Placebo Blank Analysis. A placebo blank of commonly employed tablet excipients, consisting of talc $(10 \mathrm{mg})$, starch (5 mg), acacia (5 mg), methyl cellulose (10 mg), sodium citrate $(5 \mathrm{mg})$, magnesium stearate $(10 \mathrm{mg})$, and sodium alginate $(5 \mathrm{mg})$, was made and its solution was prepared as described under "procedure for tablets" and then analyzed using the procedures described above.

2.3.4. Procedure for the Determination of OFX in Synthetic Mixture. To the placebo blank of the composition described above, $25 \mathrm{mg}$ of OFX was added and homogenized, transferred to $50 \mathrm{~mL}$ volumetric flask, and the solution was prepared as described under "procedure for tablets." An aliquot $(8 \mu \mathrm{g} / \mathrm{mL}$ OFX in method A and $12 \mu \mathrm{g} / \mathrm{mL}$ OFX in method B) was then subjected to analysis by the procedures described above after appropriate dilution with dichloromethane. This analysis was performed to study the interference by excipients such as talc, starch, acacia, methyl cellulose, sodium citrate, magnesium stearate, and sodium alginate.

2.3.5. Procedure for Stoichiometric Relationship. Job's method of continuous variations of equimolar solutions was employed: $5.444 \times 10^{-5} \mathrm{M}$ each of OFX and BCP (method A) or BCG (method B) solutions in dichloromethane were prepared separately. A series of solutions was prepared in which the total volume of OFX and dye was kept at $5 \mathrm{~mL}$. The drug and dye solutions were mixed in various complementary proportions $(0: 5,1: 4,2: 3, \ldots, 5: 0$, inclusive $)$ and completed as directed under the recommended procedures. The absorbance of the resultant ion-pair complex was measured at $400 \mathrm{~nm}$ in method $\mathrm{A}$ and $410 \mathrm{~nm}$ in method $\mathrm{B}$.

\section{Results and Discussion}

The proposed procedures are based on the reaction between OFX and BCP or BCG, resulting in the formation of yellow ion-pair complexes which could be measured directly in dichloromethane.

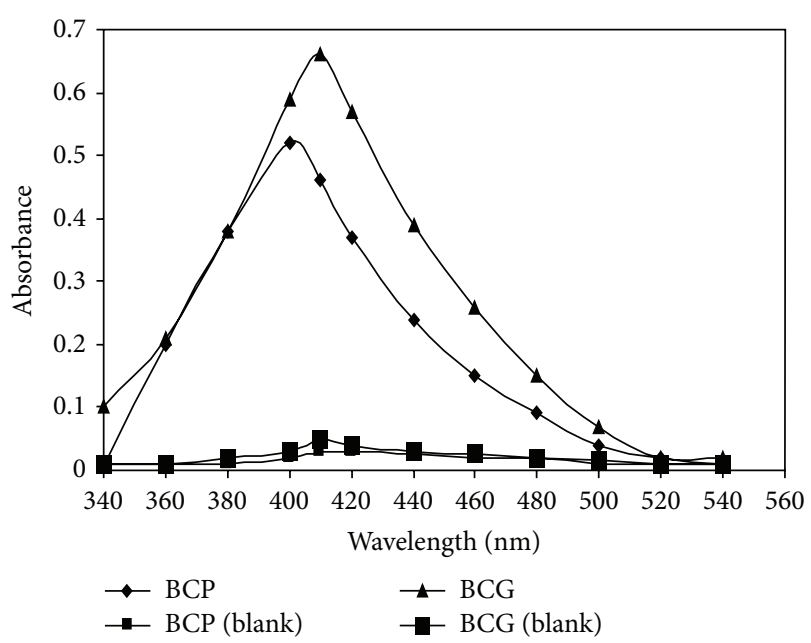

FIGURE 2: Absorption spectra of ion-pair complexes (OFX $8 \mu \mathrm{g} / \mathrm{mL}$ ): BCP $(0.1 \%)$ and OFX $(12 \mu \mathrm{g} / \mathrm{mL})$ : BCG $(0.1 \%))$ against respective reagent blank.

3.1. Absorption Spectra. OFX features a piperazine ring. This structure suggests the possibility of utilizing anionic dyes as chromogenic agents. In dichloromethane, OFX does not absorb in the visible region. Also, the dyes used have almost negligible absorbance (Figure 2). In contrast, when a solution of BCP or BCG in dichloromethane is mixed with the drug solution also in dichloromethane, an intense yellow color is immediately produced with the absorption maximum at $400 \mathrm{~nm}$ in method A and at $410 \mathrm{~nm}$ in method B (Figure 2). This is due to the conversion of the dye into an open quinoidal anionic derivative $[33,34]$, which subsequently forms an ion pair with OFX as shown in Scheme 1.

3.2. Optimization of Experimental Parameters. The experimental factors affecting the development and stability of the product were studied and optimized. Such factors include choice of the solvent, concentration of the dye, and reaction time.

3.2.1. Choice of Organic Solvent. Few organic solvents such as dichloromethane, acetone, methanol, dioxane, and carbon tetrachloride were examined since OFX is soluble in these solvents. Among these solvents, dichloromethane was preferred as the most suitable solvent to carry out the experiments because in this medium, the reagent blank gave negligible blank absorbance and the ion-pair complex formed was found to exhibit higher sensitivity and stability. In other solvents, the reagent blank yielded high absorbance value.

3.2.2. Effect of Dye Concentration. The influence of the concentration of BCP and BCG on the intensity of the color developed at the selected wavelength was studied using different amounts $(0.25-2.0 \mathrm{~mL})$ of $0.1 \%$ each of BCP and BCG in method A and in method B, respectively. As shown in Figure 3, the constant absorbance readings were obtained between 0.5 and $2.0 \mathrm{~mL}$ of $0.1 \%$ of dyes in both methods; $1 \mathrm{~mL}$ 


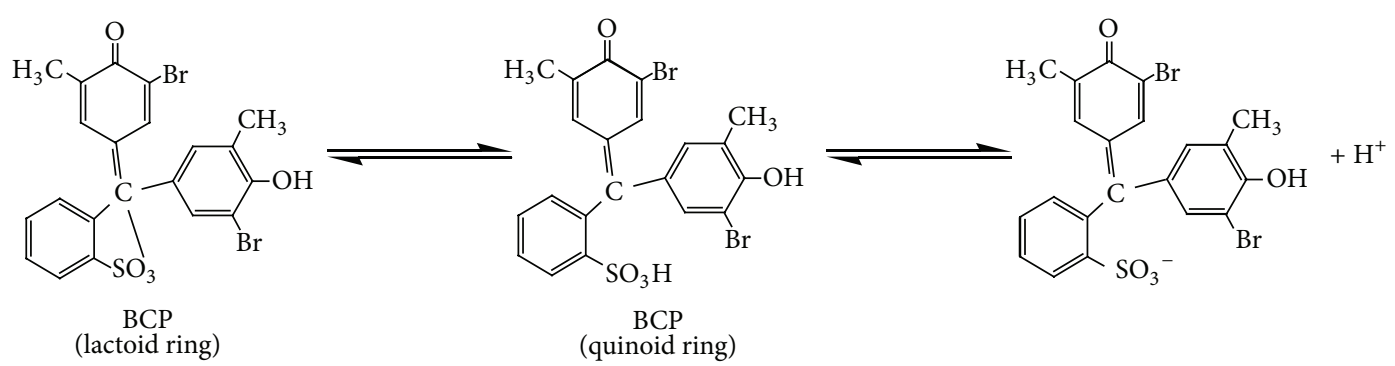

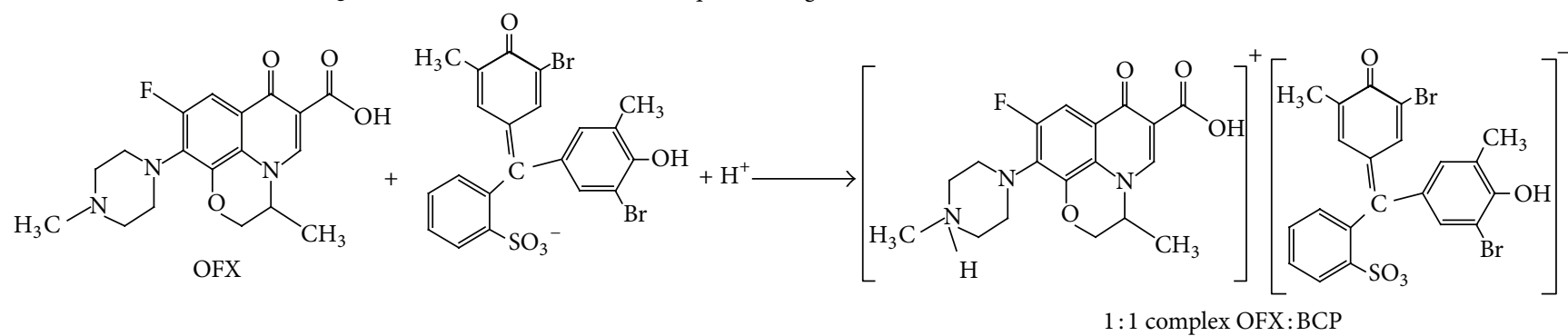

(a)<smiles>Cc1ccccc1C(OS(=O)(=O)c1ccccc1)(c1cc(Br)c(O)c(Br)c1C)c1cc(Br)c(O)c(Br)c1C</smiles>

BCG (lactoid ring)<smiles>C=C=C</smiles><smiles>Cc1c(C(c2ccccc2S(=O)(=O)O)c2cc(Br)c(O)c(Br)c2C)cc(Br)c(O)c1Br</smiles>

(quinoid ring)<smiles>CC1COc2c(N3CCN(C)CC3)c(F)cc3c(=O)c(C(=O)O)cn1c23</smiles>

OFX<smiles>Cc1c(C(c2ccccc2[S+](=O)[O-])c2cc(Br)c(O)c(Br)c2C)cc(Br)c(O)c1[PH3+]</smiles>
$\mathrm{H}^{+}$

(b)<smiles>Cc1c(C2c3ccc(c([O-])c3)-c3c([O-])ccc2c3C)cc(Br)c(O)c1Br</smiles><smiles>Cc1c(C(c2ccccc2S(=O)(=O)[O-])c2cc(Br)c(O)c(C)c2C(=O)O)cc(Br)c(O)c1Br</smiles>

$1: 1$ complex OFX:BCG

Scheme 1: Possible reaction schemes (a) OFX: BCP and (b) OFX: BCG.

of $0.1 \%$ dye solution was sufficient to produce maximum and reproducible color with minimum blank absorbance in both methods.

3.2.3. Effect of Reaction Time. The optimum reaction time for the development of color at ambient temperature $\left(25 \pm 2^{\circ} \mathrm{C}\right)$ was studied and it was found that the addition of the dye solutions resulted in an immediate full color development. The formed ion pairs were stable for at least $60 \mathrm{~min}$ in method $\mathrm{A}$ and $40 \mathrm{~min}$ in method B (Figure 4).

3.2.4. Stoichiometric Ratio. The molar ratio of OFX to dyes in the complex was determined by applying Job's method of continuous variations. In both cases, the plot reached a maximum value at a mole fraction of 0.5 which indicated

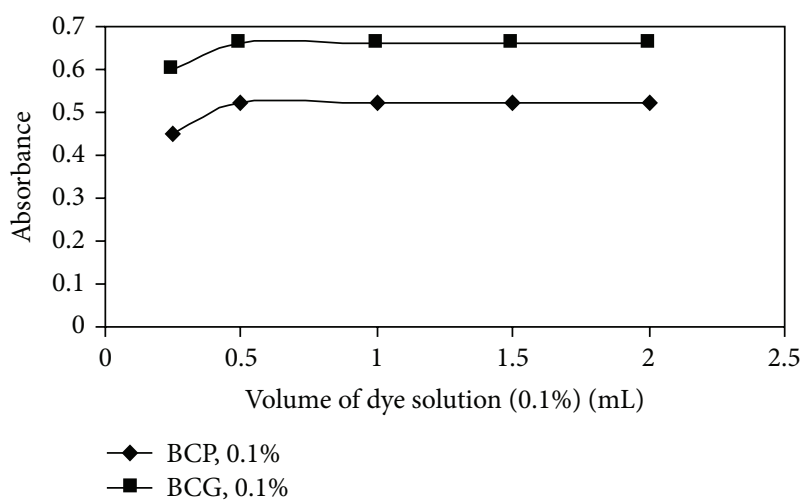

FIGURE 3: Effect of dye concentration on ion-pair formation $(8 \mu \mathrm{g} /$ $\mathrm{mL}$ OFX in method A and $12 \mu \mathrm{g} / \mathrm{mL}$ OFX in method B). 


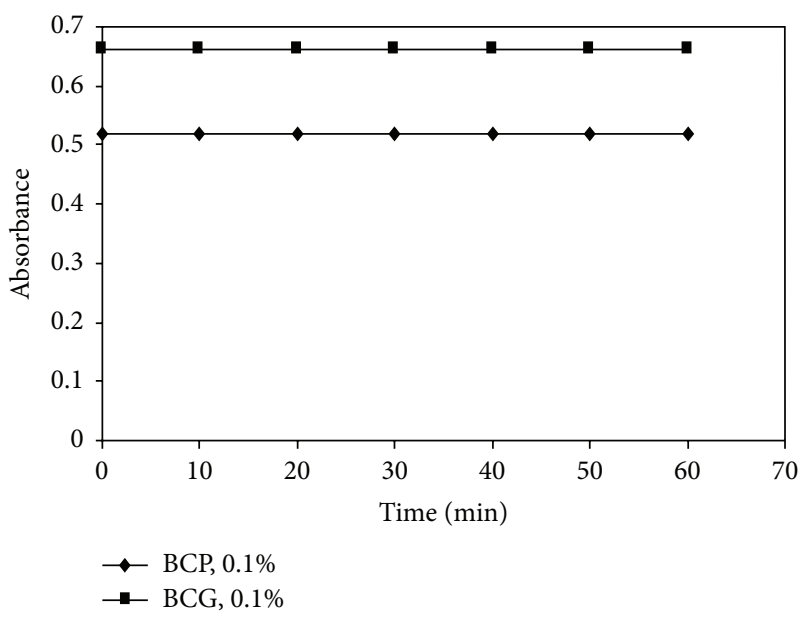

Figure 4: Effect of time $(8 \mu \mathrm{g} / \mathrm{mL}$ OFX in method A \& $12 \mu \mathrm{g} / \mathrm{mL}$ OFX in method B).

the formation of 1: 1(OFX : dye) complex (Figure 5). Based on this, it was confirmed that only one nitrogen atom in the drug is protonated and through the electrostatic attraction ionpair complex is formed with the negatively charged dye. In OFX, the nitrogen atom bonded to electron donating methyl group in the piperazine ring is the most vulnerable one for protonation [35]. The reaction pathway is shown in Scheme 1.

3.2.5. Conditional Stability Constants $\left(K_{f}\right)$ of the Ion-Pair Complexes. The conditional stability constants $\left(K_{f}\right)$ of the ion-pair complexes were calculated from the continuous variation data using the following equation [36]:

$$
K_{f}=\frac{A / A_{m}}{\left[1-A / A_{m}\right]^{n+2} C_{M}(n)^{n}},
$$

where $A$ and $A_{m}$ are the observed maximum absorbance and the absorbance value when all the drug present is associated, respectively. $C_{M}$ is the mole concentration of drug at the maximum absorbance and $n$ is the stoichiometry with which dye ion associates with drug. The $\log K_{f}$ values for OFXBCP and OFX-BCG ion-pair associates were 7.481 and 7.418, respectively.

3.3. Method Validation. The proposed methods were validated for linearity, sensitivity, precision, accuracy, robustness, ruggedness, specificity, and interferenceand recovery.

3.3.1. Linearity and Sensitivity. Under optimum experimental conditions, linear correlations were obtained between the absorbance and concentration of OFX in the range of 1.0$16.0 \mu \mathrm{g} / \mathrm{mL}$ (method A and method B), as shown in Figure 6. The calibration graph is described by the equation:

$$
Y=a+b X
$$

where $Y$ is absorbance, $a$ is intercept, $b$ is slope, and $X$ is concentration in $\mu \mathrm{g} / \mathrm{mL}$, obtained by the method of least squares. Correlation coefficient, intercept, and slope for the calibration data are summarized in Table 2. Sensitivity

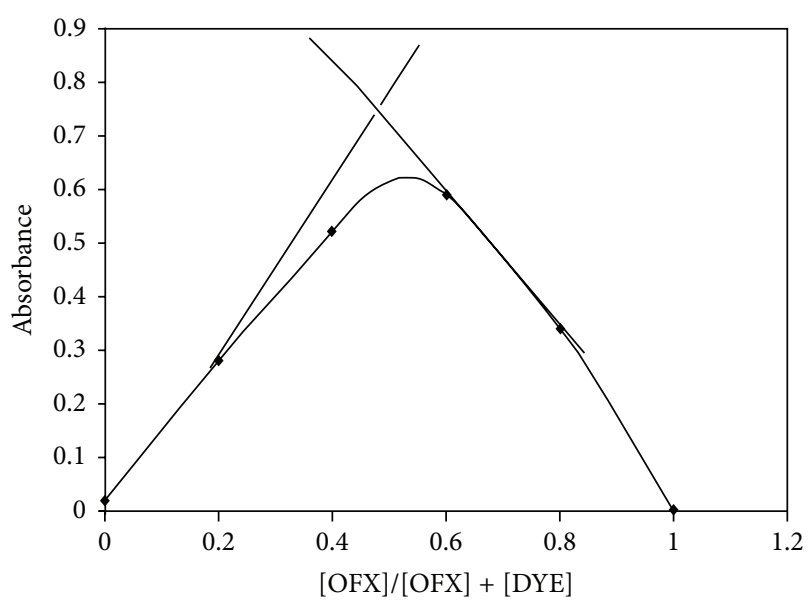

(a)

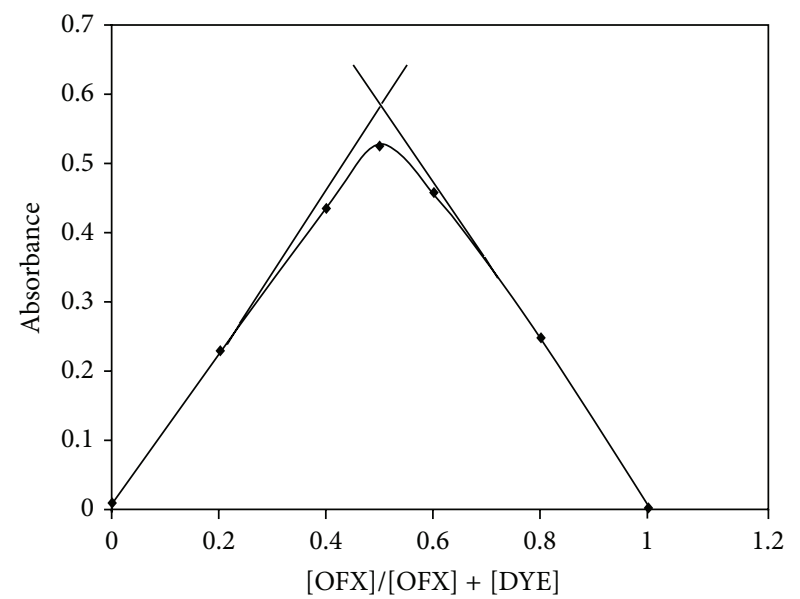

(b)

FIGURE 5: Job's continuous variations plots: (a) OFX-BCP and (b) OFX-BCG.

TABLE 2: Sensitivity and regression parameters.

\begin{tabular}{lcc}
\hline Parameter & Method A & Method B \\
\hline$\lambda_{\text {max }}, \mathrm{nm}$ & 400 & 410 \\
Linear range, $\mu \mathrm{g} / \mathrm{mL}$ & $1.0-16.0$ & $1.0-16.0$ \\
Molar absorptivity $(\varepsilon), \mathrm{L} / \mathrm{mol} / \mathrm{cm}$ & $2.40 \times 10^{4}$ & $1.96 \times 10^{4}$ \\
Sandell's sensitivity ${ }^{*}, \mu \mathrm{g} / \mathrm{cm}^{2}$ & 0.015 & 0.019 \\
Limit of detection (LOD), $\mu \mathrm{g} / \mathrm{mL}$ & 0.11 & 0.09 \\
Limit of quantification $(\mathrm{LOQ}), \mu \mathrm{g} / \mathrm{mL}$ & 0.32 & 0.27 \\
Regression equation, $Y^{* *}$ & & \\
$\quad$ Intercept $(a)$ & 0.003 & 0.012 \\
$\quad$ Slope $(b)$ & 0.061 & 0.051 \\
$\quad$ Standard deviation of $a\left(S_{a}\right)$ & 0.126 & 0.040 \\
$\quad$ Standard deviation of $b\left(S_{b}\right)$ & 0.008 & 0.003 \\
$\quad$ Regression coefficient $(r)$ & 0.999 & 0.999 \\
\hline
\end{tabular}

${ }^{*}$ Limit of determination as the weight in $\mu \mathrm{g}$ per $\mathrm{mL}$ of solution, which corresponds to an absorbance of $A=0.001$ measured in a cuvette of crosssectional area $1 \mathrm{~cm}^{2}$ and $l=1 \mathrm{~cm} .{ }^{* *} Y=a+b X$, where $Y$ is the absorbance, $X$ is concentration in $\mu \mathrm{g} / \mathrm{mL}, a$ is intercept, and $b$ is slope.

parameters such as apparent molar absorptivity and Sandell's sensitivity values, the limits of detection and quantification 


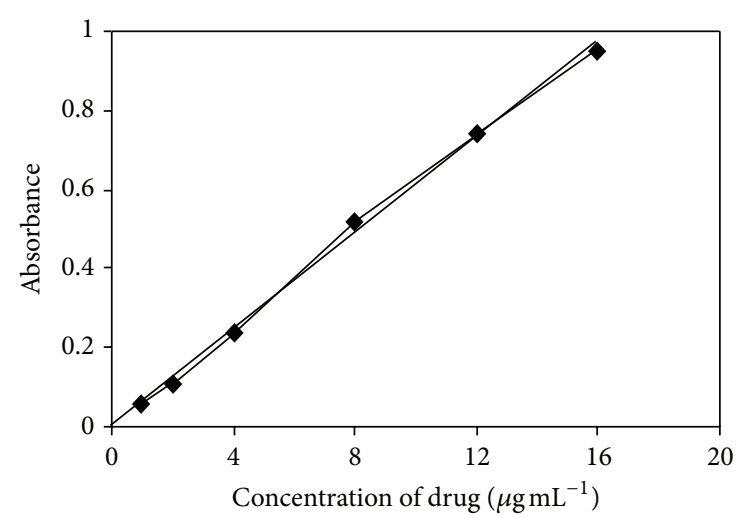

(a)

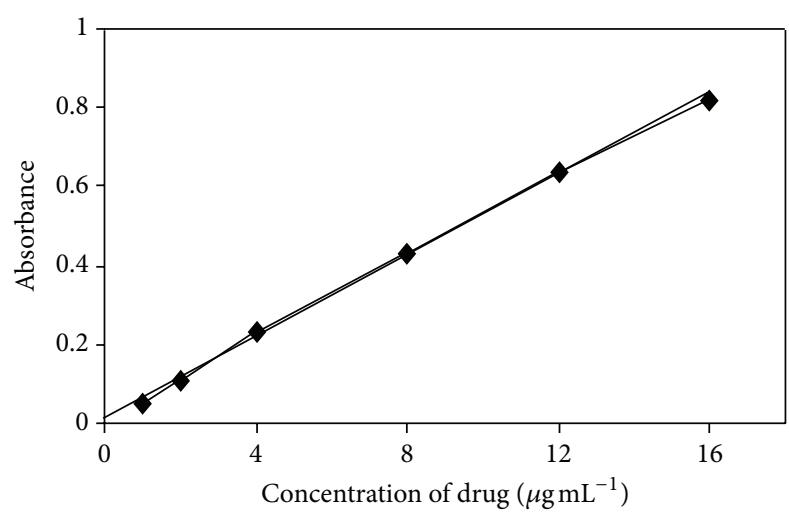

(b)

FIGURE 6: Calibration curves: (a) OFX-BCP and (b) OFX-BCG.

TABLE 3: Evaluation of intraday and interday accuracy and precision.

\begin{tabular}{|c|c|c|c|c|c|c|c|}
\hline \multirow{2}{*}{ Method } & \multirow{2}{*}{ OFX taken $(\mu \mathrm{g} / \mathrm{mL})$} & \multicolumn{3}{|c|}{ Intraday accuracy and precision } & \multicolumn{3}{|c|}{ Interday accuracy and precision } \\
\hline & & OFX found $(\mu \mathrm{g} / \mathrm{mL})$ & $\% \mathrm{RE}$ & $\%$ RSD & OFX found $(\mu \mathrm{g} / \mathrm{mL})$ & $\% \mathrm{RE}$ & $\%$ RSD \\
\hline \multirow{3}{*}{ Method A } & 8.00 & 7.83 & 2.13 & 1.02 & 7.76 & 2.98 & 1.18 \\
\hline & 12.0 & 11.77 & 1.92 & 1.14 & 11.68 & 2.66 & 1.29 \\
\hline & 16.0 & 15.61 & 2.44 & 1.22 & 15.50 & 3.11 & 1.31 \\
\hline \multirow{3}{*}{ Method B } & 8.00 & 7.85 & 1.88 & 1.17 & 7.77 & 2.87 & 1.24 \\
\hline & 12.0 & 11.71 & 2.45 & 1.04 & 11.64 & 3.00 & 1.13 \\
\hline & 16.0 & 15.68 & 1.97 & 1.21 & 15.60 & 2.50 & 1.29 \\
\hline
\end{tabular}

RE: relative error and RSD: relative standard deviation.

are calculated as per the current ICH guidelines [37] and are compiled in the same table, speaking of the excellent sensitivity of the proposed method. The limits of detection (LOD) and quantification (LOQ) were calculated using the formulae:

$$
\mathrm{LOD}=3.3 \sigma / s \quad \mathrm{LOQ}=10 \sigma / s
$$

where $\sigma$ is the standard deviation of five reagent blank determinations and $s$ is the slope of the calibration curve.

3.3.2. Precision and Accuracy. In order to evaluate the precision of the proposed methods, solutions containing three different concentrations of the OFX were prepared and analyzed in seven replicates. The analytical results obtained from this investigation are summarized in Table 3. The low values of the relative standard deviation (\% RSD) and percentage relative error (\% RE) indicate the high precision and the good accuracy of the proposed methods. The percentage relative error is calculated using the following equation:

$$
\% \mathrm{RE}=\left[\frac{\text { found }- \text { taken }}{\text { taken }}\right] \times 100
$$

The assay procedure was repeated seven times, and percentage relative standard deviation (\% RSD) values were obtained within the same day to evaluate repeatability (intraday precision) and over five different days to evaluate intermediate precision (interday precision).
TABLE 4: Recovery of the drug from synthetic mixture.

\begin{tabular}{lcc}
\hline Method & $\begin{array}{c}\text { OFX in synthetic mixture taken, } \\
\mu \mathrm{g} / \mathrm{mL}\end{array}$ & $\begin{array}{c}\text { OFX recovered }^{\mathrm{a}} \\
(\text { Percent } \pm \mathrm{SD})\end{array}$ \\
\hline \multirow{3}{*}{ Method A } & 8.0 & $101.6 \pm 1.15$ \\
& 12.0 & $100.9 \pm 1.21$ \\
& 16.0 & $102.5 \pm 1.13$ \\
\hline \multirow{3}{*}{ Method B } & 8.0 & $103.18 \pm 1.18$ \\
& 12.0 & $102.61 \pm 1.11$ \\
& 16.0 & $103.7 \pm 1.23$ \\
\hline
\end{tabular}

${ }^{\mathrm{a}}$ Mean value of five determinations.

3.3.3. Specificity and Interference. The interferences likely to be produced from coformulated were studied by placebo blank and synthetic mixture analyses. A convenient aliquot of the placebo blank solution prepared above was subject to analysis according to the recommended procedures. In both cases, there was no interference from the inactive ingredients, indicating a high selectivity for determining OFX in its dosage forms.

A separate experiment was performed with the synthetic mixture. The analysis of synthetic mixture solution prepared above yielded percent recoveries which ranged from 100.9 to 103.7 with standard deviation of 1.11-1.23 in both cases. The results of this study are presented in Table 4 indicating that the inactive ingredients did not interfere in the assay. These results further demonstrate the accuracy as well as the precision of the proposed methods. 
TABLE 5: Results of analysis of tablets by the proposed methods.

\begin{tabular}{|c|c|c|c|c|}
\hline \multirow{2}{*}{ Tablet brand name } & \multirow{2}{*}{ Label claim, mg/tablet } & \multicolumn{3}{|c|}{ Found $^{*}$ (percent of label claim \pm SD) } \\
\hline & & Reference method & Method A & Method B \\
\hline \multirow{3}{*}{ Zenflox- $400^{* *}$} & & & $98.12 \pm 1.14$ & $101.2 \pm 1.19$ \\
\hline & 20 & $99.82 \pm 1.05$ & $t=2.45$ & $t=1.95$ \\
\hline & & & $F=1.15$ & $F=1.28$ \\
\hline \multirow{3}{*}{ Ofloxin- $400^{* * *}$} & & & $101.9 \pm 1.15$ & $102.1 \pm 1.13$ \\
\hline & 20 & $100.9 \pm 1.10$ & $t=1.40$ & $t=1.70$ \\
\hline & & & $F=1.09$ & $F=1.06$ \\
\hline
\end{tabular}

${ }^{*}$ Mean value of five determinations.

${ }^{* *}$ Mankind Pharma Pvt Ltd., New Delhi, India; ${ }^{* * *}$ J. B. Chemicals and Pharmaceuticals Ltd., Mumbai, India.

The value of $t$ (tabulated) at $95 \%$ confidence level and for four degrees of freedom is 2.77 .

The value of $F$ (tabulated) at $95 \%$ confidence level and for four degrees of freedom is 6.39.

TABLE 6: Accuracy assessment by recovery experiments.

\begin{tabular}{lccccc}
\hline Method & Tablet studied & $\begin{array}{c}\text { OFX in tablet } \\
(\mu \mathrm{g} / \mathrm{mL})\end{array}$ & $\begin{array}{c}\text { Pure OFX added } \\
(\mu \mathrm{g} / \mathrm{mL})\end{array}$ & $\begin{array}{c}\text { Total found } \\
(\mu \mathrm{g} / \mathrm{mL})\end{array}$ & $\begin{array}{c}\text { Pure OFX recovered }^{*} \\
\text { Percent } \pm \text { SD }\end{array}$ \\
\hline \multirow{3}{*}{ Method A } & Ofloxin-400 & 4.08 & 2.0 & 6.06 & $99.00 \pm 1.21$ \\
& & 4.08 & 4.0 & 8.03 & 9.06 \\
\hline \multirow{3}{*}{ Method B } & & 4.08 & 6.0 & 6.10 & $99.67 \pm 1.15$ \\
& & 4.08 & 2.0 & 8.20 & $101.0 \pm 1.17$ \\
& & 4.08 & 4.0 & 10.17 & $102.9 \pm 1.09$ \\
\hline
\end{tabular}

${ }^{*}$ Mean value of three measurements.

3.3.4. Application to Tablets. In order to evaluate the analytical applicability of the proposed methods to the quantification of OFX in commercial tablets, the results obtained by the proposed methods were compared to those of the reference method [4] by applying Student's $t$-test for accuracy and $F$ test for precision. The results (Table 5) showed that the Student's $t$ - and $F$-values at $95 \%$ confidence level did not exceed the tabulated values, which confirmed that there is a good agreement between the results obtained by the proposed methods and the reference method with respect to accuracy and precision.

3.3.5. Recovery Studies. The accuracy and validity of the proposed methods were further ascertained by performing recovery studies. Preanalysed tablet powder was spiked with pure OFX at three concentration levels $(50,100$, and $150 \%$ of that in tablet powder) and the total was found by the proposed methods. In both cases, the added OFX recovery percentage values ranged from 99.00 to $102.9 \%$ with standard deviation of 1.09-1.21 (Table 6) indicating that the recovery was good, and that the coformulated substance did not interfere in the determination.

\section{Conclusions}

This paper describes for the first time the application of ionpair-based extraction-free spectrophotometric technique for the determination of OFX in pharmaceutical formulation. Unlike the other reported methods [12-15, 19], the proposed methods are very simple, free from the use of auxiliary reagents and expensive instruments. The reported visible spectrophotometric methods based on oxidative-coupling reaction [23] uses an expensive reagent, and the reaction product is less stable. The method based on condensation reaction [24] involves boiling for $20 \mathrm{~min}$. Complexation reaction procedures suffer from such limitations as strict $\mathrm{pH}$ control [25] and poor sensitivity (linear range 20-160 $\mu \mathrm{g} / \mathrm{mL}$ ) [26]. Extractive spectrophotometric methods [27, 28] based on ion-pair complex formation reactions, though sensitive and selective, are devoid of simplicity since critical pH control and liquid-liquid extraction step are involved.

The proposed methods are the most sensitive ever reported for the spectrophotometric determination of OFX (Table 1). The most attractive feature of the methods is their relative freedom from interference by the usual tablet diluents and excipients in amounts far in excess of their normal occurrence in pharmaceutical formulations. The high accuracy and precision of the methods may be attributed to the absence of experimental variables which normally would affect the absorbance values. Hence, recommended methods are well suited for the assay and evaluation of drug in pharmaceutical industrial quality control.

\section{Acknowledgments}

The authors wish to thank Cipla India Ltd., Mumbai, India, for providing the gift sample of ofloxacin. Two of the authors (Kudige N. Prashanth and Madihalli S. Raghu) thank the authorities of the University of Mysore, India, for their kind permission and facilities to carry out the research work. 


\section{References}

[1] A. Goodman, L. S. Goodman, T. W. Hall et al., Las Bases Farmacologicas de la Terapeutica, McGraw-Hill Interamericana, Madrid, Spain, 1989.

[2] N. Ichihara, H. Tachizawa, M. Tusumura et al., "Phase I study on DL-8280," Chemotherapy, vol. 32, pp. 118-149, 1984.

[3] United States Pharmacopoeia, National Formulary XVII, vol. 22, Convention, Rockville, Md, USA, 1990.

[4] British Pharmacopeia, Her Majesty's, vol. 3, Stationery Office, London, UK, 2003.

[5] A. P. Argekar, S. U. Kapadia, S. V. Raj, and S. S. Kunjir, "Quantitative determination of lomefloxacin, ofloxacin, pefloxacin and enrofloxacin in pharmaceutical dosages, bulk drugs and process monitoring of enrofloxacin by HPLC-RP," Indian Drugs, vol. 33, no. 6, pp. 261-266, 1996.

[6] G. Carlucci, P. Mazzeo, and T. Fantozzi, "Determination of ofloxacin in pharmaceutical forms by high-performance liquid chromatography and derivative UV-spectrophotometry," Analytical Letters, vol. 26, no. 10, pp. 2193-2201, 1993.

[7] V. M. Shinde, B. S. Desai, and N. M. Tendolkar, "Selective determination of fluoroquinolone derivatives from tablets by reverse phase HPLC," Indian Drugs, vol. 35, no. 11, pp. 715-717, 1998.

[8] R. Kalta, R. Sharma, and S. Chaturvedi, "Simultaneous RPHPLC determination of nitazoxanide and ofloxacin in combined tablet dosage form," Indian Journal of Pharmaceutical Sciences, vol. 70, no. 4, pp. 491-494, 2008.

[9] B. Srividya, R. M. Cardoza, and P. D. Amin, "Stability indicating HPTLC method of analysis of ofloxacin," Indian Drugs, vol. 40, no. 1, pp. 41-43, 2003.

[10] A. A. Elbashir, B. Saad, A. S. M. Ali, M. I. Saleh, and H. Y. AboulEnein, "Determination of ofloxacin enantiomers in pharmaceutical formulations by capillary electrophoresis," Journal of Liquid Chromatography and Related Technologies, vol. 31, no. 3, pp. 348-360, 2008.

[11] S. W. Sun and A. C. Wu, "Determination of fluoroquinolone antibacterials in pharmaceutical formulations by capillary electrophoresis," Journal of Liquid Chromatography and Related Technologies, vol. 22, no. 2, pp. 281-296, 1999.

[12] H. Salem, "Spectrofluorimetric, atomic absorption spectrometric and spectrophotometric determination of some fluoroquinolones," American Journal of Applied Sciences, vol. 2, pp. 719-729, 2005.

[13] P. S. Francis and J. L. Adcock, "Chemiluminescence methods for the determination of ofloxacin," Analytica Chimica Acta, vol. 541, no. 1-2, pp. 3-12, 2005.

[14] H. Sun, L. Li, and X. Chen, "Flow-injection chemiluminescence determination of ofloxacin and levofloxacin in pharmaceutical preparations and biological fluids," Analytical Sciences, vol. 22, no. 8, pp. 1145-1149, 2006.

[15] J. Murillo, M. Alanon, I. Munaz et al., "Resolution of ofloxacinciprofloxacin and ofloxacin-norfloxacin binary mixtures by flow-injection chemiluminescence in combination with partial least squares multivariate calibration," Journal of Fluorescence, vol. 17, no. 5, pp. 481-491, 2007.

[16] J. D. Fegade, H. P. Mehta, R. Y. Chaudhari, and V. R. Patil, "Simultanious spectrophotometric estimation of ofloxacin and ketorolac tromethamine in ophthalmic dosage form," International Journal of ChemTech Research, vol. 1, no. 2, pp. 189-194, 2009.

[17] K. P. Bhusari and D. R. Chaple, "Simultaneous spectrophotometric estimation of ofloxacin and ornidazole in tablet dosage form," Asian Journal of Research in Chemistry, vol. 2, pp. 60-62, 2009.

[18] P. D. Panzade and K. R. Mahadik, "Simultaneous estimation of ofloxacin and tinidazole in tablet dosage form," Indian Drugs, vol. 38, no. 7, pp. 368-370, 2001.

[19] A. Tamer, "Adsorptive stripping voltammetric determination of ofloxacin," Analytica Chimica Acta, vol. 231, no. 1, pp. 129-131, 1990.

[20] M. Tuncel and Z. Atkosar, "The determination of ofloxacin in tablets by potentiometry and conductometry," Pharmazie, vol. 47, no. 8, pp. 642-643, 1992.

[21] G. Zhou and J. Pan, "Polarographic and voltammetric behaviour of ofloxacin and its analytical application," Analytica Chimica Acta, vol. 307, no. 1, pp. 49-53, 1995.

[22] L. da Silveira Ev and E. E. S. Schapoval, "Microbiological assay for determination of ofloxacin injection," Journal of Pharmaceutical and Biomedical Analysis, vol. 27, no. 1-2, pp. 91-96, 2002.

[23] C. S. P. Sastry, K. Rama Rao, and D. Siva Prasad, "Spectrophotometric determination of enrofloxacin and ofloxacin in pharmaceutical formulations," Indian Drugs, vol. 32, no. 4, pp. 172-175, 1995.

[24] P. U. Patel, B. N. Suhagia, M. M. Patel, G. C. Patel, and G. N. Patel, "Spectrophotometric determination of ofloxacin with citric acid-acetic anhydride," The Indian Pharmacist, vol. 6, pp. 5961, 2007.

[25] C. J. Eboka, S. O. Aigbavboa, and J. O. Akerele, "Colorimetric determination of the fluoroquinolones," Journal of Antimicrobial Chemotherapy, vol. 39, no. 5, pp. 639-641, 1997.

[26] S. C. Mathur, Y. Kumar, N. Murugesan, Y. K. S. Rathore, and P. D. Sethi, "Spectrophotometric determination of ofloxacin in pharmaceutical formulations," Indian Drugs, vol. 29, no. 8, pp. 376-377, 1992.

[27] C. S. P. Sastry, K. Rama Rao, and D. Siva Prasad, "Extractive spectrophotometric determination of some fluoroquinolone derivatives in pure and dosage forms," Talanta, vol. 42, no. 3, pp. 311-316, 1995.

[28] Y. M. Issa, F. M. Abdel-Gawad, M. A. Abou Table, and H. M. Hussein, "Spectrophotometric determination of ofloxacin and lomefloxacin hydrochloride with some sulphonphthalein dyes," Analytical Letters, vol. 30, no. 11, pp. 2071-2084, 1997.

[29] H. Abdine, F. Belal, and N. Zoman, "Simple spectrophotometric determination of cinnarizine in its dosage forms," Farmaco, vol. 57, no. 4, pp. 267-271, 2002.

[30] S. M. Al-Ghannam, "A simple spectrophotometric method for the determination of $\beta$-blockers in dosage forms," Journal of Pharmaceutical and Biomedical Analysis, vol. 40, no. 1, pp. 151156, 2006.

[31] P. Shahdousti, M. Aghamohammadi, and N. Alizadeh, "Spectrophotometric study of the charge-transfer and ion-pair complexation of methamphetamine with some acceptors," Spectrochimica Acta A, vol. 69, no. 4, pp. 1195-1200, 2008.

[32] D. H. Manjunatha, S. M. T. Shaikh, K. Harikrishna, R. Sudhirkumar, P. B. Kandagal, and J. Seetharamappa, "Simple and sensitive spectrophotometric methods for the determination of acebutolol hydrochloride in bulk sample and pharmaceutical preparations," Ecletica Quimica, vol. 33, no. 2, pp. 37-40, 2008.

[33] S. Ashour, M. F. Chehna, and R. Bayram, "Spectrophotometric determination of alfuzosin $\mathrm{HCl}$ in pharmaceutical formulations with some sulphonephthalein dyes," International Journal of Biomedical Sciences, vol. 2, pp. 273-278, 2006. 
[34] T. Higuchi and E. Brochmann-Hanssen, Pharmaceutical Analysis, Interscience Publication, New York, NY, USA, 1961.

[35] K. Harikrishna, B. S. Nagaralli, and J. Seetharamappa, "Extractive spectrophotometric determination of sildenafil citrate (Viagra) in pure and pharmaceutical formulations," Journal of Food and Drug Analysis, vol. 16, no. 1, pp. 11-17, 2008.

[36] A. S. Amin, A. A. El-Fetouh Gouda, R. El-Sheikh, and F. Zahran, "Spectrophotometric determination of gatifloxacin in pure form and in pharmaceutical formulation," Spectrochimica Acta A, vol. 67, no. 5, pp. 1306-1312, 2007.

[37] International Conference on Harmonisation of Technical Requirements for Registration of Pharmaceuticals for Human Use, ICH Harmonised Tripartite Guideline, Validation of Analytical Procedures: Text and Methodology, Q2 (R1), Complementary Guideline on Methodology, London, UK, 2005. 

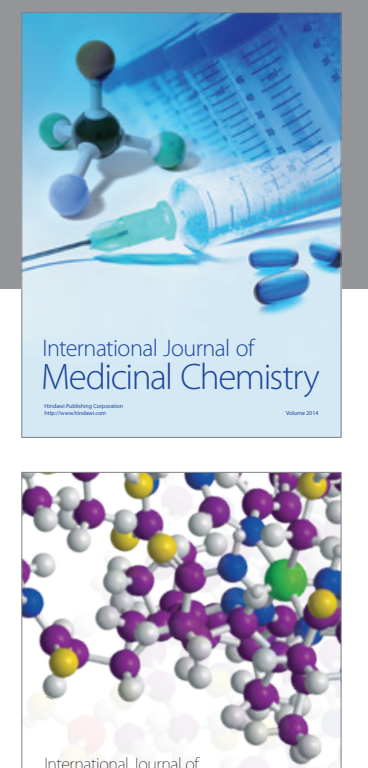

\section{Carbohydrate} Chemistry

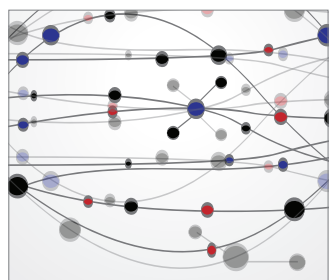

The Scientific World Journal
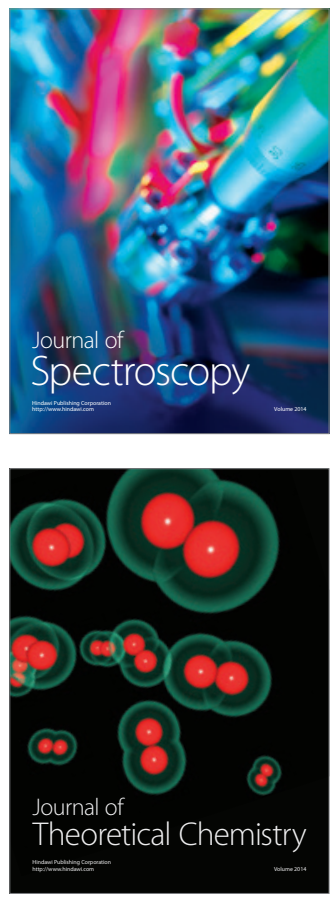
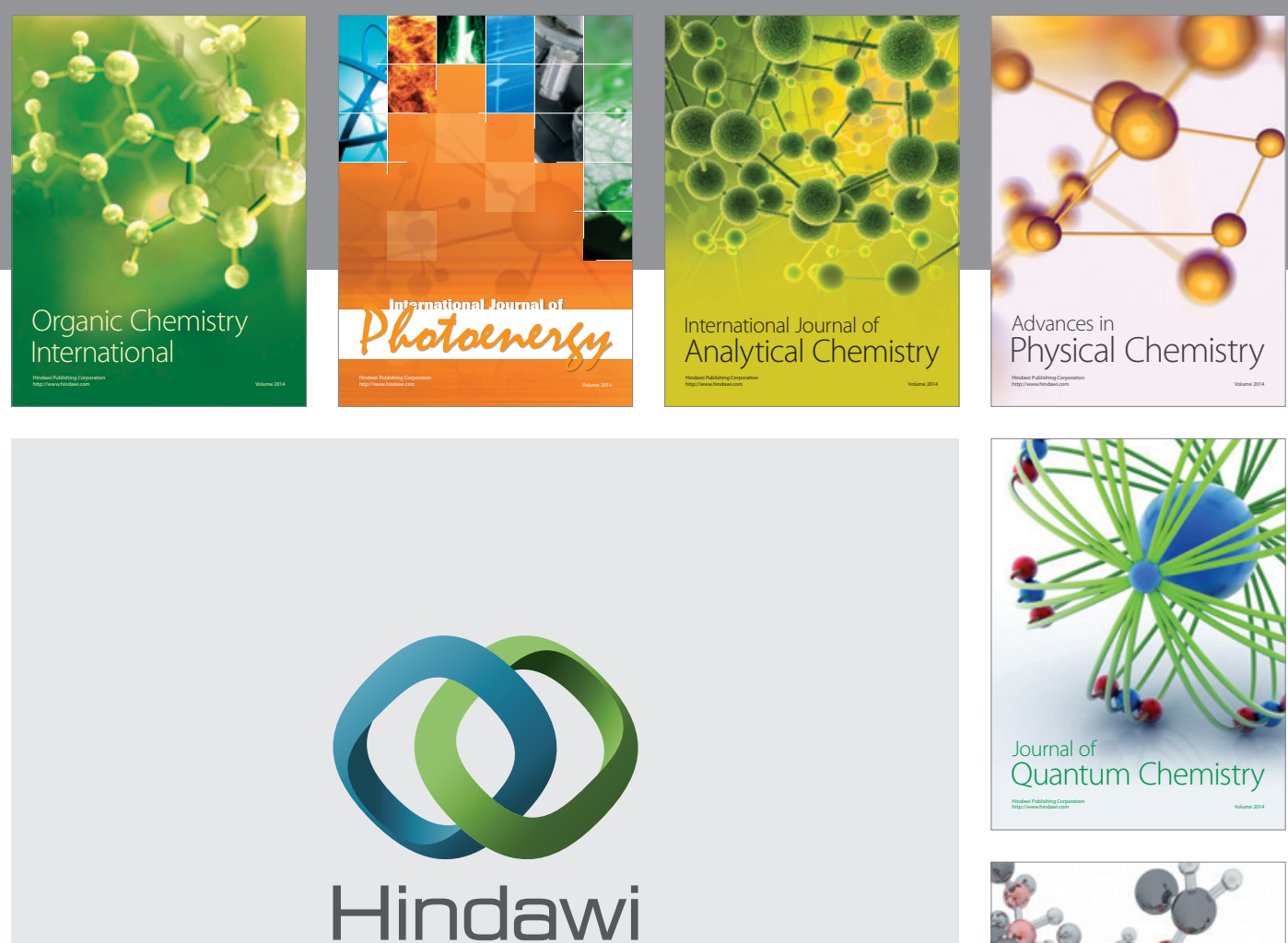

Submit your manuscripts at

http://www.hindawi.com

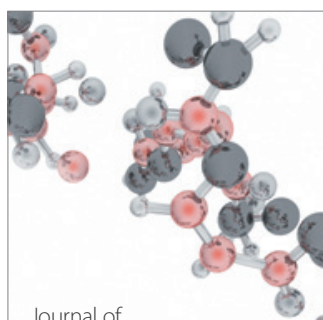

Analytical Methods

in Chemistry

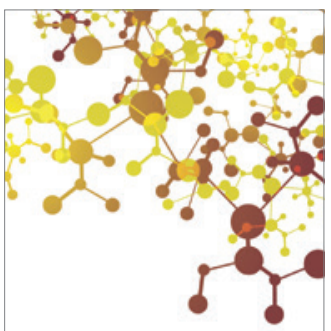

Journal of

Applied Chemistry

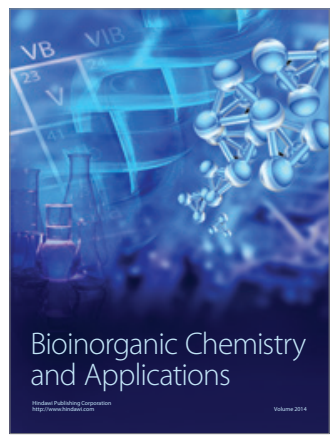

Inorganic Chemistry
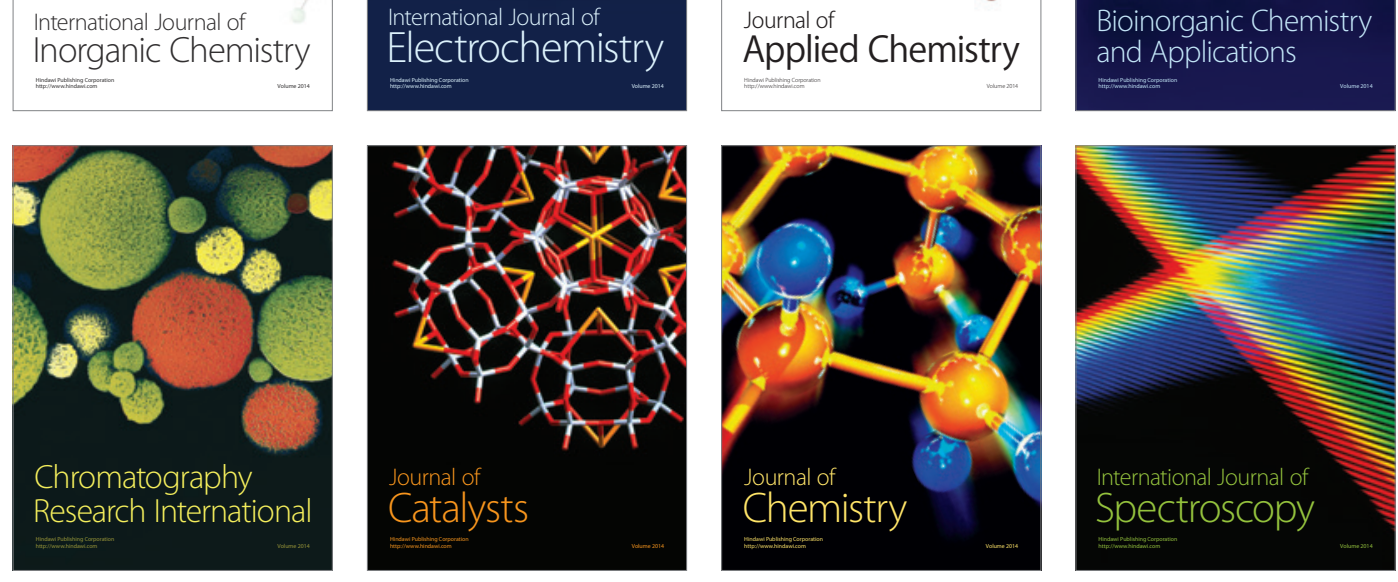